\title{
Increasing Out-Of-Pocket Health Care Expenditure in India-Due to Supply or Demand?
}

\author{
Jayakrishnan $\mathrm{T}^{1^{*}}$, Jeeja $\mathbf{M C}^{2}$, Kuniyil $\mathbf{V}^{1}$ and Paramasivam $\mathbf{S}^{1}$
}

${ }^{1}$ Department of Community Medicine, Government Medical College, Calicut, Kerala, India

${ }^{2}$ Department of Pharmacology, Government Medical College, Calicut, Kerala, India

*Corresponding author: Thayyil Jayakrishnan, Department of Community Medicine, Government Medical College, Calicut, Kerala, India, Tel: 04952355737; E-mail: drjayakrishnant@yahoo.com

Received date: October 21, 2015; Accepted date: February 22, 2016; Published date: February 29, 2016

Copyright: ( $) 2016$ Jayakrishnan T, et al. This is an open-access article distributed under the terms of the Creative Commons Attribution License, which permits unrestricted use, distribution, and reproduction in any medium, provided the original author and source are credited.

\begin{abstract}
Introduction:After a gap of ten years the information regarding morbidity and health expenditure in Indian states were collected in detail National Sample Survey Organization (NSSO) and were published on June 30th, 2015. During this decade the country and health system has undergone major changes including introduction of public funded health insurance schemes (PFHI). This paper was done with the objectives to study the OOP health expenditure and factors affecting it and to understand the impact PFHI on OOP in India.
\end{abstract}

Method: Study done by reviewing, analysing the availing data from NSSO survey conducted during 2014 and 2004 and for assessing the impact of PFHI schemes on OOP other published studies on evaluation of PFHI schemes were included.

Results: Proportion of Ailing Persons (PAP) was 104 per 1000 with 13 points increase during the last ten years. The utilization of public services for outpatient $(\mathrm{O})$ care like subcenters, primary health enter, Community health centres were $25 \%$ and inpatient (IP) care was $40 \%$. OP expenditure has increased $>100 \%$ and IP care expenditure almost $300 \%$ increased during last ten years. More than $80 \%$ of the expenditure are met by out of pocket (OOP).Rural households primarily depended on their 'household income / savings' (68\%) and on 'borrowings' (25\%), the urban households relied much more on their 'income / saving' $(75 \%)$ for financing expenditure on hospitalizations, and on '(18\%) borrowings. Even from the upper quintile, both rural and urban areas have borrowed money to meet the hospital expenditure which was $23 \%$ and $14 \%$ respectively. Only $12 \%$ urban and $13 \%$ rural population received any protection coverage through any of the PFHI like "Rashtriya Swasthya Bhima yojana" (RSBY).

Conclusion: The morbidities cost per illness episode were inevitably increased in the last decade in India. The increase in life expectancy, demographic change of more aged population coupled with chronic disease will increase the morbidity and health expenditure in the future. Unless overt reliance on unregulated private sector are systematically corrected by alternative health financing mechanisms and strengthening public health system "right for health" will be a distant dream for common citizens.

Keywords: Morbidity; Hospitalization; Out of pocket expenditure; publicly funded Health insurance; RSBY

\section{Introduction}

Health and demographic surveys play an important role in India where the health reporting system is not efficient enough to collect valid information for policy formulation and measuring progress [1].The only such survey regularly conducted is the National Sample Survey Organization (NSSO) by the Ministry of Statistics and Program Implementation which is the primary source of basic quantitative information [2,3]. The key indicators of social consumption in India' was published on June $30^{\text {th }}, 2015$ which threw light on the information regarding morbidity and health expenditure as analyzed by the NSSO 2014 (NSS $71^{\text {st }}$ round), after a gap of 10 years. During this decade, various programs were undertaken by Central and State Governments and the health system underwent major changes which were captured by this survey. India is currently the world's third largest economy in terms of gross national income and has the potential to grow larger in a more equitably [1]. The second important change in this context is the emergence of a 'health care industry' growing at 15\% compound annual growth rate despite the global economic slowdown $[1,4]$. Even though there exists a positive correlation of economic growth with improved health indicators, such a trend has not been observed in India [4]. Thirdly, the incidence of Catastrophic Healthcare Expenditure (CHE) is growing and is now estimated to be one of the major contributors to poverty [1]. Health care costs are more impoverishing than ever before and almost all hospitalizations, even in public hospitals leads to $\mathrm{CHE}$ and over 63 million people are facing poverty every year due to health care costs alone [1]. Healthcare access in India is affected with 70:70 paradox; 70 per cent of healthcare expenses are incurred by people from their pockets, of which 70 per cent is spent on medicines alone, leading to impoverishment and indebtedness [4]. For decades, economic planners of India regarded health expenditure as financially nonproductive social spending and public financing levels were low and total spending on healthcare was about $4.1 \%$ of GDP [5]. Global evidence on health spending shows that unless a country spends at least $5-6 \%$ of its GDP on health and the 
major part of it is from government expenditure, basic health care needs are seldom met [1]. The Government expenditure on healthcare in India is only $1.04 \%$ of GDP which is about $4 \%$ of total expenditure, less than $30 \%$ of total health spending which is Rs. 957 per capita at current market prices ( 1 US dollar $=65.04$ Indian Rupee). On per capita basis the Central Government's share of this is Rs. 325 while state government's share is Rs. 632 [1].

The flagship program, National Rural Health Mission (NRHM), which led to decentralized operations and infrastructure strengthening was launched in 2005 [5]. NRHM framework proposed increasing public health expenditure to $2 \%-3 \%$ of the GDP but it stagnated at $1.04 \%$ [1]. The Central Government's Ministry of Labor and Employment, in 2008, launched the Rashtriya Swasthya Bhima Yojana (RSBY), a health insurance scheme which enrolled 400 million people from below poverty line (BPL) families [1,6]. In 2010, the Planning Commission of India convened a high level expert group (HLEG) on universal health coverage (UHC) which recommended increasing public financing from $1 \%$ of the GDP to at least $2.5 \%$ and an essential health care package and free provision of essential drugs and diagnostics [5]. Due to the arguments that this increased investment in health will impede economic growth, the proposal was not implemented in the 12th plan $[5,6]$. As directed by the Supreme Court, the government had formulated Drug Price Control Order (DPCO) in 2013 which received severe criticism on it's methodology on fixing ceiling price by market based pricing (MBP) instead of cost based price (CBP) to reduce cost of drugs [7]. The current Indian Government released a draft National Health Policy (NHP) in January 2015, which promised 'national health assurance. This explicitly addresses the enactment of the 'right to health' through parliamentary legislation but allows states to decide the services to be included in the right $[1,5]$. States which have achieved a per capita public health expenditure rate of over Rs. 3800 (at current prices) should be in a position to deliver on this [1]. India's key health indicators are as follows: Life expectancy at birth 66 year, Crude death rate 8,Infant mortality rate of 41 , maternal mortality ratio of 167 , Sex ratio 914 , Bed population ratio of 0.7 [1,5]. This paper was done with the objectives to study the OOP health expenditure and factors affecting it and to understand the impact of public funded health insurance schemes (PFHI) on OOP in India.

\section{Method}

This review paper was done by analyzing data from the NSSO survey conducted during January to June 2014 and comparing it with the previous NSSO survey conducted during 2004. For assessing the impact of PFHI schemes on OOP, other published studies on evaluation of PFHI schemes were also included by literature search. The expenditure values were given in Indian rupees and for comparison; values were adjusted for inflation by taking base year as 2000 and inflation correction factors 1.134, 1.554 for 2004 and 2014 respectively. During NSSO survey 2014, the following information regarding health was collected in detail. The particulars of spells of ailments of household members during the last 15 days, particulars of medical treatment received as inpatient of a medical institution during the last 365 days and the respective expenses incurred for treatment. The information on distribution of households and population by income level is useful for a correlative study on morbidity and health care. As a proxy of income, data on Monthly Percapita Consumption Expenditure (MPCE), which is the sum total of monetary values of all goods and services consumed out of pocket or procured otherwise by the household on domestic account were collected [3]. The variables for rural and urban population, public and private health care were analyzed and discussed for comparison.

\section{Results}

\section{Morbidity and health}

Proportion of Ailing Persons (PAP) was collected by self-reported morbidity. The current PAP rose to 104 per 1000 from 91 per 1000 as reported during the last survey, which is a 13 point rise during the last decade (Table 1).The age wise trend at national level is depicted in Table 1. Age group 30 - 59 show marked increase in morbidity, mainly due increased prevalence of NCDs attributed due to life style changes. Kerala state showed the highest PAP (308/1000). Urban areas have a higher PAP than rural areas (89 and 118 per thousand population respectively) (Table 2) and as per the previous survey, the PAP has increased by 1 and 19 points respectively. There was a positive association between MPCE and PAP and the difference between the lowest and highest quintile was almost double in both urban and rural areas (Rural 65:131, Urban 79:156 per 1000) (Table 3). This phenomenon of high morbidity in affluent class and in urban areas may be due to cultural inflation of morbidity.

\begin{tabular}{|c|c|c|c|}
\hline \multirow{2}{*}{$\begin{array}{l}\text { Age } \quad \text { group } \\
\text { Years }\end{array}$} & \multicolumn{2}{|c|}{ Year of Survey } & \multirow{2}{*}{$\begin{array}{l}\text { Difference within last } 10 \\
\text { years }\end{array}$} \\
\hline & PAP 2004 & PAP 2014 & \\
\hline $0-14$ & 74 & 74 & Nil \\
\hline $15-29$ & 49 & 47 & -02 \\
\hline $30-44$ & 78 & 88 & +10 \\
\hline $45-59$ & 128 & 170 & +42 \\
\hline Above 60 & 304 & 307 & +03 \\
\hline All age groups & 91 & 104 & +13 \\
\hline
\end{tabular}

Table 1: Prevalence of reported morbidity (PAP) within 15 day recall period per 1000.

\begin{tabular}{|l|l|l|}
\hline Variables & \multicolumn{2}{l|}{ India 2014 } \\
\cline { 2 - 4 } & Rural & Urban \\
\hline Morbidity during 15 days / 1000 & 89 & 118 \\
\hline OP treatment -Public health facility\% & 21 & 28 \\
\hline $\begin{array}{l}\text { Expenditure for OP treatment 15 day } \\
\text { period-Indian Rupees }\end{array}$ & $509(328)^{*}$ & $639(411)^{*}$ \\
\hline $\begin{array}{l}\text { Hospitalization during last 365 days / 1000 } \\
\text { IP treatment - Public health facility\% }\end{array}$ & 35 & 42 \\
\hline $\begin{array}{l}\text { Expenditure for IP treatment- Indian } \\
\text { Rupees }\end{array}$ & $14935(9611)^{*}$ & $24436(15725)^{*}$ \\
\hline $\begin{array}{l}\text { Expenditure for Hospital delivery- Indian } \\
\text { Rupees }\end{array}$ & $5544(3568)^{*}$ & $11685(7519)^{*}$ \\
\hline $\begin{array}{l}\text { Any public health Insurance( RSBY)support } \\
\%\end{array}$ & 13 & 12 \\
\hline \begin{tabular}{l} 
Borrowing \% \\
\hline NB: *Backets - Inflation adjusted values in Indian rupees
\end{tabular} & 18 \\
\hline
\end{tabular}

Table 2: Curative treatment and direct expenditure in India. 
Hospitalization is a nonfatal health outcome that is considered to be relatively free from errors associated with reporting illness and can be used as a proxy indicator of severe morbidity. Hospitalization rates were found to be higher in urban than rural areas ( 35 and 44 per 1000 population) (Table 2). The previous survey reported the rate to be 31 per 1000 persons.

\begin{tabular}{|l|l|l|l|l|l|l|}
\hline $\begin{array}{l}\text { Income } \\
\text { Class } \\
\text { Quintile }\end{array}$ & \multicolumn{2}{|l|}{$\begin{array}{l}\text { MPCE } \\
\text { Indian Rupees }\end{array}$} & \multicolumn{2}{|l|}{$\begin{array}{l}\text { OP Morbidity } \\
\text { Prevalence } \\
\text { thousand }\end{array}$} & \multicolumn{2}{l|}{$\begin{array}{l}\text { OP } \\
\text { Expenditure } \\
\text { Indian Rupees }\end{array}$} \\
\cline { 2 - 7 } & Rural & Urban & Rural & Urban & Rural & Urban \\
\hline 1 & 800 & 1182 & 65 & 79 & $524(337)$ & $476(306)$ \\
\hline 2 & 1000 & 1600 & 73 & 101 & $415(267)$ & $482(310)$ \\
\hline 3 & 1264 & 2200 & 85 & 124 & $469(302)$ & $553(356)$ \\
\hline 4 & 1667 & 3200 & 93 & 127 & $454(292)$ & $721(464)$ \\
\hline 5 & $>166$ & $>3200$ & 131 & 156 & $618(398)$ & $828(533)$ \\
\hline
\end{tabular}

NB: ( ) Brackets - Inflation adjusted values in Indian rupees.

Table 3: Income class wise details of morbidity, expenditure.

\section{Utilization of services: OP care}

Allopathic treatment was prevalent in all areas for outpatient treatment (OP) $90 \%$. Only 5 to $7 \%$ used other modes of treatment including AYUSH (Ayurveda, Yoga or Naturopathy Unani, Siddha and homoeopathy) and the rest did not seek any providers for treatment or underwent self-treatment. Untreated spells were more in the lowest quintile class ranging from 32 to 21 per thousand. Seventy (70\%) sought treatment from private health facilities, of which $50 \%$ were from private practicing doctors/clinics. The utilization of public services like Sub Centers, Primary Health Centers (PHC) and Community Health Centers showed an increase to 25\% from $20.5 \%$ during the last survey (Table 2). Public services were more utilized by the urban population for OP care $(21 \%, 28 \%)$ (Table 2$)$ which may be attributed to accessibility and availability issues in rural areas.

\section{Utilization of services: IP care}

Allopathic care was preferred for inpatient care by $99 \%$ during the reference period out of which $40 \%$ utilized public health services. Thirty two per cent in urban areas and $42 \%$ in rural areas were hospitalized in public hospitals. The utilization of public IP service showed a decreasing trend of $44 \%, 42 \%$, and $42 \%$ in rural and $43 \%$, $38 \%, 32 \%$ in urban areas in 1995-96, 2004, 2014 NSSO surveys respectively. The higher shift in urban areas to private hospitals may be due to the increase in number of hospitals and beds as well as empanelling more private hospitals in PFHI schemes. The utilization of the public sector hospitals in IP in different MPCE quintiles shows a negative correlation from $58 \%$ to $29 \%$ in rural areas and $48 \%$ to $19 \%$ in urban areas (Table 4).

\begin{tabular}{|c|c|c|c|c|c|c|c|c|c|c|}
\hline \multirow[t]{2}{*}{$\begin{array}{l}\text { Income Class } \\
\text { Quintile }\end{array}$} & \multicolumn{2}{|c|}{ Indian Rupees MPCE } & \multicolumn{2}{|c|}{$\begin{array}{l}\text { Hospitalization Public } \\
\text { sector Utilization \% }\end{array}$} & \multicolumn{2}{|c|}{$\begin{array}{l}\text { Hospitalization } \\
\text { Expenditure Indian } \\
\text { Rupees }\end{array}$} & \multicolumn{2}{|c|}{ Any PFHI Coverage \% } & \multicolumn{2}{|c|}{ Borrowing \% } \\
\hline & Rural & Urban & Rural & Urban & Rural & Urban & Rural & Urban & Rural & Urban \\
\hline 1 & 800 & 1182 & 57.5 & 48 & $\begin{array}{l}10146 \\
(6529)\end{array}$ & $\begin{array}{l}11199 \\
(7155)\end{array}$ & 10.1 & 7.7 & 26.8 & 21.7 \\
\hline 2 & 1000 & 1600 & 52.9 & 43.5 & $\begin{array}{l}11276 \\
(7256\end{array}$ & $\begin{array}{l}14533 \\
(9352)\end{array}$ & 10.7 & 10.6 & 25.8 & 21.9 \\
\hline 3 & 1264 & 2200 & 47.1 & 32.7 & $\begin{array}{l}10326 \\
(6645\end{array}$ & $\begin{array}{l}17926 \\
(11535)\end{array}$ & 11.9 & 12.9 & 25.3 & 20.7 \\
\hline 4 & 1667 & 3200 & 42.8 & 28.3 & $\begin{array}{l}13482 \\
(8676\end{array}$ & $\begin{array}{l}24776 \\
(15943)\end{array}$ & 15.9 & 13.5 & 26.0 & 18.1 \\
\hline 5 & $>1667$ & $>3200$ & 28.9 & 18.7 & $\begin{array}{l}21293 \\
(13702\end{array}$ & $\begin{array}{l}42675 \\
(27461)\end{array}$ & 17.0 & 15.1 & 23.1 & 13.7 \\
\hline
\end{tabular}

Table 4: Income class wise details of hospitalization, expenditure, meeting expenditure.

By virtue of advancement in medical science along with the availability of oral medications, most medical conditions can be managed at OP level which should reduce the hospitalization rate. This is not so in India, which might be due to the influence of private sectors and the induced demand by health insurances. Health care has shifted from primary care to secondary or higher levels due to supplier induced demands and moral hazard problems, where excess inappropriate or unnecessary medical care is consumed or utilized [8]. There is only a minor increase in utilization of OP care and no increase in IP care facilities in public facilities comparable to the infrastructure and manpower input via the NRHM. According to the Bulletin on Rural Health Statistics in India, there is a shortage of 36346 Sub 
Centers, 6700 PHCs and 2350 CHCs [9]. In addition, there exists a crippling shortage of human resources at all levels of public healthcare delivery system which divert people from public facilities. Added to this there is a shift in the health care choice to secondary or tertiary cares centers, most of which are in private sectors. The national health programs that address communicable diseases and provide free of cost treatment from public health facilities represent less than $6 \%$ of all morbidities and about $25 \%$ of all communicable diseases which again forces people to choose private facilities [1].

\section{Treatment expenditure: OP care}

More than $2 / 3$ of the treatment expenditure was attributed to direct expenditure [10-13] which is also the consideration in this study. During the 15 days recall period, the combined average percapita treatment expenditure as OOP for OP care per episode was reported to be Rs. 574 (Rural - 509,Urban - 639) (Table 2). During the survey in 2004, it was Rs. 282. Adjusting inflation makes it Rs. 369 and Rs. 249 with an increase of $50 \%$. Even in a PHCs people incurred expenditure as OOP (Range Rs. 309-386), comes to about $50 \%$ of the average percapita OP expenditure. It was mainly spent on users' fee, outside prescribed drugs and laboratory investigations, which indicate the lack of availability of these services in most of the PHCs [1]. The prescribed drugs were not available at PHCs due to higher drug costs in the market indicating the impact of DPCO 2013 on decreasing drug prices [7]. In urban areas, OP expenditure was positively correlated with the wealth quintile (Table 3). In NSSO 2004, 33\% (95\% CI: 32.3-33.4) of the households reported OOP payments for OP care (10). Outpatient OOP payments instigated a catastrophic health expenditure (CHE) of $73.1 \%$ in a large proportion of households relative to IP payments [10].

\section{Treatment expenditure: IP care}

During the 365 days period, the average direct expenditure for IP care was Rs 18268. It was Rs. 8851 during 2004 and adjusting inflation makes it Rs 11755 and 7805 respectively with an increase of 50\%. The average expenditure at a private hospital was Rs. 25850 which was 4 fold higher than at public hospitals (Rs. 6120) which is an evidence of cost escalation in private sectors. The expenditure for IP treatment ranges from Rs. 12000 to Rs. 45000 in different quintiles. It corresponds to 15 fold of per capita MPCE of lower quintiles (Rs. 800) and 7 fold of upper quintiles (Rs. 1667) in rural areas (Table 4). The highest expenditure was recorded for cancer treatment (Rs. 56712) followed by cardio-vascular diseases (Rs. 31647). For cancer treatment, an average of Rs. 24526 was spent in public hospitals, whereas more than three times of the same was spent (Rs. 78050) in private hospitals. The proportion of number of persons affected, numbers of events, the aggregate annual expenditure of households are higher for OP care. A study conducted in five north Indian states reported that half the hospitalized spent more than $23 \%$ of their annual income for healthcare [13]. An increasing number of households (18\%) were facing CHE in 2011 - 2012 compared to 15\% in 2004 - 2005 and is still increasing [1]. Like the high degree of health inequity in health outcomes and access to health care services for vulnerable groups, there exists urban-rural inequities and inequities across the states too $[1,6,7]$. A study found that half the population spent an amount equivalent to at least $73 \%(38 \%-120 \%)$ of the monthly per capita income for one illness episode. Since drugs are used frequently on an aggregated basis, they accounted for $49 \%$ of total costs whereas hospitalizations accounted for only $11 \%$ [13].

\section{Treatment expenditure: Delivery care}

Expenditure for delivery was Rs. 1855 in public and Rs. 17550 in private hospitals. Utilization of private sector for hospital delivery is reflected on the higher expenditure for hospital deliveries in urban areas (Table 2). The DLHS-3 data reported that OOP for delivery in private hospitals was three times higher than in public hospitals [14]. The increased rate of delivery care was partially attributed to increased caesarian sections (CS) which accounts for the six times higher cost than a normal delivery [14]. National Family Health Survey (NFHS-3, 2005 - 2006) indicates that in at least six states (Kerala, Goa, Andhra Pradesh, Tamil Nadu, Karnataka and Punjab) CS rates are above 15\% [8]. An evaluation of the Chiranjeevi Yojana program in Gujarat reported that it was not associated with changes in the probability of institutional delivery, maternal morbidity or delivery-related household expenditure [15].

\section{Sources of financing to meet expenditure}

More than $80 \%$ of the expenditure is met by OOP which is consistent with reports of the previous NSSO rounds [5,10]. Rural households primarily depended on their 'household income / savings' (68\%) and on 'borrowings' (25\%), whereas the urban households relied much more on their 'income / saving' (75\%) and (18\%) on borrowings for financing expenditure on hospitalizations (Table 2). In 2004, $41 \%$ of rural and $23 \%$ of urban population met the hospital expenditure by borrowing cash, a reduction of $16 \%$ and $5 \%$, which may be partially due to improvement in economic conditions and RSBY. Even the upper income quintiles in both rural (23\%) and urban areas (14\%) have borrowed money to meet the hospital expenditure (Table 4).

Eighty percent of rural population and $82 \%$ of urban population were still not covered under any PHFI scheme. Only $12 \%$ urban and $13 \%$ rural population received any protection coverage through PFHI schemes. The MPCE quintile wise data on protection coverage clearly depicts the picture of 'inverse care law' in PFHI schemes (Table 4). This was similarly reported in Maharashtra, where the prevalence of hospitalization was almost two and a half times higher among persons belonging to the 'better-off' quintile than persons belonging to the poorest quintile among families enrolled in RSBY [11].

\section{Impact of publicly financed health insurance schemes (PFHI) on OOP expenditure}

A number of PFHI were introduced to improve access to hospitalization services and to protect households from high medical expenses. Eight states introduced PFHI programmes for covering tertiary care need and over time expenditure increased in many of these States [1]. The population coverage under these various schemes increased to about 370 million (almost one-fourth of the population) of which two thirds (180 million) belonged to the Below Poverty Line (BPL) category [1]. Under the RSBY, a maximum of five members in a BPL family can be enrolled and are entitled to receive secondary-level inpatient care up to an annual sum of Rs. 30,000 on floater basis. The scheme has established a network of hospitals and the enrolled people can seek cashless inpatient care from these hospitals [11]. There is an ongoing debate on methodologies used for categorizing households into BPL or APL to be included in RSBY, since the upper quintiles got more benefits as evident in the NSSO survey (Table 4).In Maharashtra, on analysis of available literature on BPL household consumption expenditure revealed that more than half of them were actually non poor households [11]. Compared to rural, the urban households 
enrolled in RSBY faced a higher rate of catastrophic inpatient expenditure (CIE). Almost half of the previously enrolled households were not continuing with the program revealing its non-acceptability. Notably, having RSBY coverage had no significant effect on CIE among families with $<5$ or $>5$ members [11]. The poorer economic groups with PFHI experienced an increase incidence of CHE, mainly due to an increase in OOP spending on IP care [11]. The scheme also does not deal with OP care which aggregates $60 \%$ cost of medical expenditure of the family, which pushes non-poor households into poverty and the poor further deeper into it. $[10,11,16]$. A study of RSBY in Gujarat showed no considerable difference between the OOP expenditure of insured and uninsured cohorts [16].

As an evidence of moral hazard from demand side, the hospitalization rates were found to be higher among the RSBY enrolled people (8.3\%) than their non-RSBY counterparts (5\%) [11]. Another issue is that these schemes are encouraging an unequal competition between the private corporate hospitals and resource starved public health facilities to attract beneficiaries [11]. As reported in the health policy document, evaluations show that schemes such as the RSBY have improved utilization of hospital services, especially in private sector and among the poorest $20 \%$ of households [1]. As a moral hazard, private hospitals also induced demand of uncovered services by overcharging them $[11,12]$. In Maharashtra, the total amount of claims in RSBY never crossed $57 \%$ of the total premiums taken and the claim ratio was just about $42 \%$ in the last five years. Hence the role of commercial insurance companies in PFHIs needs to be critically evaluated $[11,16]$. It was estimated that after introduction of PFHI involving private hospitals the direct government expenditure on tertiary care which was actually $20 \%$, raised to $37 \%$ [16]. The denial of services by private hospitals for many categories of illnesses, over supply of some services, insurance companies and administrators engaging in various fraudulent measures including charging informal payments were also reported in the evaluation [1].

In April 2007, Andhra Pradesh state Government implemented a community health insurance scheme, the Rajiv Aarogyasri Scheme (RAS) for all poor families who constituted $88 \%$ of the state's population by cashless IP coverage [12]. Following this, the average OOP payments among the hospitalized households increased to around Rs. 28,000 which was almost totally financed through loans and sale of assets. The diversion of patients from public hospitals to private hospitals who are forced to pay OOP once they find that their disease is not covered under the RAS is probably a reason for the increased share of IP expenditure [12]. It was shown that the RAS scheme drew $25 \%$ of the state's health budget while covering only $2 \%$ of the burden of disease [16]. The available evidence questions the scheme's ability to offer financial protection and reduce OOP spending efficiently.

Impoverishment due to medical expenditure following the neoliberal doctrines which increased the involvement of private sector in medical care was predicted earlier by many authors $[8,16]$. The proportion of households that incur CHE in a country is widely used as an indicator of the extent to which the health system protects households needing health care against financial hardships and offering such protection is one of its major goals [10]. It is widely acknowledged that low OOP spending and high government health expenditure (GHE) is a sign of a good and functional health system [12]. The drain on family incomes due to health care costs can neutralize the gains of income and every government scheme aimed to reduce poverty.

\section{Conclusion}

We conclude that the morbidities and cost per illness episode were inevitably increased in the last decade in India mainly due to supply induced demands. The increase in life expectancy and the demographic change of aged population coupled with chronic diseases will increase the morbidity and health expenditure in the future. Unless the overt reliance on unregulated private sectors is systematically corrected by alternative health financing mechanisms and strengthening the public health system, 'right to health' will be a distant dream for a common citizen. A comprehensive review of RSBY and other currently fragmented government funded healthcare schemes should be conducted with the aim of future consolidation for a national program ensuring universal healthcare. The Government should be the primary provider of healthcare and the enforcement of healthcare for all should not be based on expansion of health insurance based models. Establishment of standard treatment protocols ensuring quality healthcare and regulation of the private sector must be a priority for reducing health care expenditure.

\section{References}

1. Government of India (2014) National health policy draft. Ministry of Health and Family Welfare, Government of India, New Delhi.

2. Morbidity Health care and the condition of the aged (2006) NSSO 60th Round - (January -June 2004) National Sample Survey Organization. Ministry of Statistics and Programme Implementation. Government of India.

3. Government of India (2015) Key Indicators of Social Consumption in India Health. NSS 71 Round. January - June 2014. Ministry of Statistics and Programme Implementation. National Sample Survey Office.

4. Golechha M (2015) Healthcare agenda for the Indian government. Indian J Med Res 141: 151-153.

5. Reddy KS (2015) India's Aspirations for Universal Health Coverage. New England Journal of Medicine 373: 1-5.

6. Hooda SK (2013) Changing Pattern of Public Expenditure on Health in India, Issues and Challenges. ISID, PHFI Collaborative Research Centre Institute for Studies in Industrial Development.

7. Srinivasan S, Srikrishna T, Phadke A (2013) Drug price control order 2013. As good as a leaky bucket. Economic and Political Weekly 48: 10-12.

8. Mazumdar S (2015) Murky Waters of Medical Practice in India. Ethics, Economics and Politics of Healthcare. Economic and Political Weekly 50: 40-54.

9. Government of India (2014) Rural Health Statistics. Statistical division, Ministry of Health and Family Welfare, Government of India, New Delhi, 2013-2014.

10. Raban MZ, Dandona R, Dandona L (2013) Variations in catastrophic health expenditure estimates from household surveys in India. Bulletin of the World Health Organization 91: 726-735.

11. Ghosh S (2014) Publicly-Financed Health Insurance for the Poor Understanding RSBY in Maharashtra. Economic and Political Weekly 49: 93-99.

12. Nagulapalli S (2014) Burden of Out-of-Pocket Health Payments in Andhra Pradesh. Economic and Political Weekly 49: 64-72.

13. Dror DM, Putten-Rademaker V, Koren R (2008) Cost of illness: evidence from a study in five resource-poor locations in India. Indian J med Res 127: 347-361.

14. Sanjay K Mohanty, Akanksha Srivastava (2013) Out-of-pocket expenditure on institutional delivery in India. Health Policy and Planning 28: 247-262.

15. Mohanan M, Bauhoff S, La Forgia G, Babiarz KS, Singh K, et al. (2014) Effect of Chiranjeevi Yojana on institutional deliveries and neonatal and 
Citation: Jayakrishnan T, Jeeja MC , Kuniyil V, Paramasivam S (2016) Increasing Out-Of-Pocket Health Care Expenditure in India-Due to Supply or Demand? Pharmacoeconomics 1: 105.

Page 6 of 6

maternal outcomes in Gujarat, India: a difference-in-differences analysis. Bull World Health 92: 187-194.
16. Kurian O (2015) Financing Healthcare for all in India: Towards a Common Goal: Oxfam India. Copernicus Marg' New Delhi. 